\title{
Política industrial e compromissos críveis: uma proposta de análise e de ação governamental
}

\author{
ROBSON ANTONIO GRASSI*
}

Industrial policy and credible commitments: a proposal of analysis and of governmental action. This paper analyses the question of the counterparts that governments should claim from firms and/or economic sectors supported by vertical industrial policy. This is a discussion that still have to advance because everything indicate that the set of current counterparts (goals of costs, productivity, exportation, etc.) still may be increased and improved, what will facilitate the assessment of industrial policy execution by society and the verification of its efficacy in order to yielding more possibilities of economic growth for a country or region. To reinforce the commitment credibility of the agents supported by industrial policy, this paper proposes to maintain the counterparts meant before and that such agents will be stimulated to commit specific assets in their activities that are supported by govern. It is shown that, without use more public resources than the used currently, this new counterpart may reinforce substantially the incentives that the firms supported by vertical industrial policy have it to execute the traditional counterparts assumed by them, and with it guarantee the best possible use of public resources.

Keywords: industrial policy; credible commitments; specific assets.

JEL Classification: L14; L52 e O38.

\section{INTRODUÇÃO}

Este artigo, partindo do princípio de que muitos países, tanto desenvolvidos como em desenvolvimento, continuam usando, de forma aberta ou dissimulada, os mais variados tipos de medidas de política industrial vertical, analisa a questão das contrapartidas que os governantes, no intuito de zelar pela melhor utilização

\footnotetext{
* Professor do Departamento de Economia e do Mestrado em Economia da Universidade Federal do Espírito Santo (UFES). E-mail: ragrassi@uol.com.br. Submetido: Julho 2006; Aprovado: Junho 2007.
} 
possível do dinheiro público, devem exigir das empresas e/ou setores da economia apoiados por tais medidas.

A questão central do artigo é que esta é uma discussão que ainda tem de avançar, pois tudo indica que o conjunto de contrapartidas exigidas pelas políticas industriais de corte vertical (metas de custos, produtividade, exportações etc.) ainda pode ser ampliado e aperfeiçoado, o que facilitaria o acompanhamento da sua execução pela sociedade e a verificação de sua eficácia no sentido de render maiores possibilidades de crescimento econômico para um país ou região.

No caso mais específico da discussão teórica sobre estas questões, também não se notam avanços no sentido de propor a criação de novos tipos de contrapartidas que sejam mais efetivas nos seus requisitos de transparência na alocação dos recursos públicos e eficiência em sua utilização.

Por isso, o objetivo deste texto é propor um novo tipo de contrapartida de política industrial, considerando-se a existência das contrapartidas "tradicionais" como o ponto de partida da análise. Mostra-se que tal debate tem de avançar no sentido de, além das contrapartidas tradicionais, propor medidas que sinalizem de forma ainda mais clara um efetivo comprometimento das empresas apoiadas com os objetivos da política governamental vigente, justificando com isso o apoio recebido.

Buscando contribuir para este debate, o presente artigo propõe, para reforçar a credibilidade do comprometimento dos agentes apoiados por uma certa política industrial, que eles sejam estimulados a comprometer ativos específicos nas atividades que exercem e que são apoiadas pelo governo. O comprometimento de ativos específicos, dado seu caráter de irreversibilidade, reforçaria o compromisso dos agentes apoiados no sentido de alcançar as metas que são estabelecidas para justificar o gasto do dinheiro público.

Para entendermos melhor esta idéia, antes é necessário apresentar a relação existente entre os ativos específicos e o estabelecimento de compromissos críveis numa relação de cooperação. Este debate já tem um razoável desenvolvimento em aplicações para relações de cooperação entre empresas, sempre a partir da análise de O. Williamson, mais especificamente de seu modelo de "refém" (Williamson, 1985). Associado à noção de "sombra do futuro" da teoria dos jogos (ver Dyer, 1997; e Parkhe, 1993), tal modelo tem permitido o estudo de como relações de cooperação entre empresas podem atingir os benefícios do aumento da confiança entre os parceiros e ao mesmo tempo a criação ou ampliação de suas vantagens competitivas.

A utilização destes elementos teóricos permite o entendimento de uma relação particular de "cooperação", entre cada empresa apoiada pela política industrial vigente (mais especificamente suas medidas verticais de política) e a agência pública encarregada de colocá-la em prática. Com isso, o artigo procura mostrar que políticas industriais verticais podem aumentar seu nível de eficiência no sentido de alcançar melhores resultados para a sociedade a partir da sua adoção. 
Evita-se entrar no mérito sobre se é necessário ou não um país ou região ter políticas industriais verticais. Apenas partimos do ponto de vista de que elas existem em boa parte dos países, e por isso podem ser aperfeiçoadas no seu calcanhar-de-aquiles, que se refere à possibilidade de uso indevido dos recursos da sociedade.

Para atingir seus objetivos, o texto divide-se em quatro partes, além desta introdução. Na seção 2 é apresentada a questão das contrapartidas exigidas pelas autoridades públicas voltadas para a política industrial, mostrando-se a insuficiência do debate atual sobre o tema e mesmo como as contrapartidas exigidas atualmente podem ser ampliadas. Na terceira seção são apresentados os elementos teóricos que norteiam a proposta acima, centrados no modelo de "refém" de Williamson e na noção de "sombra do futuro" da teoria dos jogos. A seção 4 mostra como se daria a política industrial, com a nova contrapartida aqui proposta, a partir dos elementos teóricos apresentados na seção anterior. Por fim, a última seção apresenta as conclusões do artigo.

\section{POLÍTICA INDUSTRIAL E CONTRAPARTIDAS: A INSUFICIÊNCIA DO DEBATE E DAS PRÁTICAS GOVERNAMENTAIS ATUAIS}

O tema "política industrial", além da sua inegável importância na agenda de discussões sobre políticas públicas de muitos países, também é caracterizado, como em outros assuntos econômicos, pela enorme polêmica sobre a sua necessidade, grau de utilização, efeitos etc.

Levando-se em conta que a política industrial pode ser dividida em dois tipos (horizontal e vertical), fica mais fácil entender onde se encontra o cerne da polêmica atual sobre o tema em questão. ${ }^{1}$ Enquanto medidas de política industrial de corte "horizontal" estão sujeitas a menos controvérsias por parte das mais diversas correntes heterodoxas e até de muitos economistas de orientação mais ortodoxa, é no que se refere às medidas de política "verticais" que as maiores divergências surgem. ${ }^{2}$

Sabe-se que, enquanto economistas heterodoxos costumam, em certos casos,

\footnotetext{
${ }^{1}$ Políticas industriais horizontais são aquelas que buscam melhorar o desempenho da economia na sua totalidade, sem privilegiar alguma indústria específica (exs.: medidas relacionadas com infra-estrutura, condições de crédito, propriedade intelectual, incentivos a gastos com pesquisa e desenvolvimento etc.). Por outro lado, políticas industriais verticais são aquelas que privilegiam deliberadamente uma certa indústria ou cadeia produtiva (como no caso de indústrias nascentes ou em declínio, indústrias com grande poder de encadeamento, com elevado potencial de criação de valor agregado etc.). Para maiores detalhes, ver Ferraz et al. (2002).

${ }^{2}$ Dentro do elenco de medidas de política industrial vertical podemos citar renúncia fiscal, crédito facilitado, compras governamentais, incentivo aos gastos com P\&D etc., quando tais instrumentos de política são voltados para empresas, setores ou cadeias produtivas específicas.
} 
recomendar a utilização dos mais variados tipos de apoio a setores específicos da indústria de um país ou região, no âmbito da Teoria Neoclássica estes tipos de atuação governamental costumam ser recebidos com ceticismo por parte destes economistas, tanto i) por considerarem tais medidas uma intervenção desnecessária e até contraproducente nos mecanismos de mercado; ii) como também pelo potencial de uso indevido do dinheiro público que elas apresentam (ver Ferreira e Hamdan, 2003).

Obviamente, a primeira destas duas questões é central para separar visões mais ortodoxas e heterodoxas sobre política industrial, e, ao que tudo indica, não existe possibilidade, pelo menos atualmente, de que exista algum tipo de convergência entre os dois campos teóricos tradicionais da Ciência Econômica sobre esta questão. Inclusive porque se referem a visões de mundo que dão origem às teorias e proposições de política de ambas vertentes teóricas.

Porém, no caso do segundo tipo de questão, deve-se ressaltar que não é somente a ortodoxia que se preocupa com a melhor utilização do dinheiro público. ${ }^{3}$ Cobrar "transparência" na utilização dos recursos públicos é uma exigência da sociedade moderna, nos mais diversos países, o que evidentemente se reflete nas proposições de política de qualquer corrente teórica atual.

Assim, mesmo com a predominância no mundo atual de recomendações de política de corte "neoliberal", que costumam ser bastante críticas quanto a medidas de política industrial de modo geral, e, principalmente, quanto a políticas industriais verticais, ${ }^{4}$ o fato é que muitos países (tanto desenvolvidos como em desenvolvimento) continuam usando, de forma aberta ou dissimulada, os mais variados tipos de medidas de política industrial vertical (para a experiência dos países da OCDE, ver Cassiolato, 2003, por exemplo). ${ }^{5}$

Mas, se é verdade que, mesmo com as restrições mencionadas, a utilização dos mais variados tipos de políticas industriais ainda é comum no mundo atualmente, sabe-se também que nos tempos atuais a política industrial tem de cada vez mais se mostrar efetiva em termos de custo-benefício, ou seja, tem de mostrar que pode render benefícios substanciais para a sociedade como um todo que compen-

\footnotetext{
${ }^{3}$ E no caso dos economistas brasileiros esta questão surge com grande ênfase, dado o histórico do país de políticas industriais que foram colocadas em prática em décadas passadas e nas quais o cuidado com a boa utilização dos recursos públicos não foi dos maiores. Por esta razão, alguns economistas (ver Ferreira e Hamdan, 2003, por exemplo) chegam a acusar a colocação em prática desta política industrial como parte do processo de concentração de renda historicamente presente na economia brasileira.

${ }^{4}$ E neste caso são importantes as restrições de órgãos como a Organização Mundial do Comércio $(\mathrm{OMC})$ a vários tipos de política industrial, tanto os de corte vertical como horizontal.

${ }^{5}$ Embora o alcance de tais políticas não seja mais tão amplo como antigamente. Em vários países (e este é o caso do governo brasileiro com sua mais recente proposta de política industrial, a partir de 2003) as medidas de política industrial vertical têm se restringido a atividades "estratégicas" e "portadoras de futuro", por exemplo.
} 
sem a utilização temporária (com o tempo de duração e o valor do benefício sendo definidos a priori) do dinheiro público naquela atividade apoiada.

Por isso, uma discussão cada vez mais necessária neste contexto se refere à questão das contrapartidas que os governantes, no intuito de zelar pela melhor utilização possível do dinheiro público, devem exigir das empresas e/ou setores da economia apoiados por medidas de política industrial, principalmente as verticais. $^{6}$

No que se refere à questão das contrapartidas, ${ }^{7}$ Nassif (2003), comentando a colocação em prática, enumera medidas que podem ser tomadas neste sentido, tanto quantitativas (metas de exportação, de aumento de produtividade e redução de custos, etc.) como qualitativas (melhora do padrão de qualidade etc.). E neste caso sempre é mencionado o exemplo dos países asiáticos (incluindo mais recentemente a China), que em muitas situações têm exigido das empresas apoiadas, entre outras contrapartidas, metas ambiciosas de exportação para justificar os recursos empregados (ver Nassif, 2005). ${ }^{8}$

Porém, comprometer-se com metas como as de melhoria de produtividade ou de aumento de níveis de exportação (e com isso começando a receber o apoio governamental) não significa que a empresa conseguirá cumprir tais metas. Não cumprindo, evidentemente o benefício poderá ser cortado, mas uma parte dele já terá sido gasta de forma provavelmente improdutiva ${ }^{9}$ para a sociedade. ${ }^{10}$

No caso mais específico da discussão teórica sobre estas questões, também não

\footnotetext{
${ }^{6} \mathrm{O}$ que não significa que não se possa exigir também contrapartidas nos casos de políticas industriais horizontais (como no caso da nova política indutrial brasileira, conforme veremos mais à frente). Até porque em qualquer ocasião elas sempre significarão um maior cuidado na utilização dos recursos da sociedade. $\mathrm{O}$ texto se refere na maioria dos casos às medidas de corte vertical apenas porque a maior polêmica sobre política industrial se refere a elas.

${ }^{7}$ É importante ressaltar desde já que na pesquisa para a elaboração do presente artigo constatou-se que mesmo as contrapartidas tradicionais são pouco citadas (e detalhadas) nas publicações sobre o tema e nas proposições atuais sobre política industrial. Isso revela que o tema das contrapartidas como um todo, dada sua importância, merece mais cuidado por parte dos autores que tratam do tema da política industrial, que neste ponto ainda apresenta certo grau de nebulosidade.

${ }^{8}$ Tais metas ajudam a explicar, por exemplo, a rápida escalada da indústria naval da Coréia do Sul, que, de produtora marginal na década de 1970, em pouco mais de uma década passou a disputar a liderança do mercado mundial na produção de navios (ver Grassi, 1998).

${ }^{9}$ No limite, um tipo de apoio às empresas como o crédito com taxas de juros subsidiadas, mesmo quando concedido com as devidas contrapartidas bancárias, pode servir para ganhos com arbitragem se, além de tais contrapartidas bancárias, não forem exigidas das empresas contrapartidas que se revelem efetivas na cobrança de resultados.

${ }^{10}$ Sabe-se que em certos países asiáticos o não-cumprimento de compromissos mínimos previamente exigidos significa que os empresários não somente deixarão de continuar recebendo os incentivos públicos, como também estarão sujeitos a sanções pecuniárias (ver Nassif, 2003: 61). Porém, mesmo com esta medida radical, que quando se faz necessária evidentemente deve ser tomada, acreditamos que o mecanismo de política proposto a seguir pode ser mais interessante para as empresas e também para a sociedade, pois evita que se chegue a situações como estas.
} 
se notam avanços no sentido de propor a criação de novos tipos de contrapartidas que sejam mais efetivas nos seus requisitos de transparência na alocação dos recursos públicos e eficiência na sua utilização. Exemplificando, o "dossiê" da revista Econômica (2003) sobre política industrial trouxe em suas páginas opiniões de autores de diversas correntes (tanto ortodoxas como heterodoxas) sobre o tema. Mas, ao consultar os vários textos nela contidos, o que se nota é que a questão das contrapartidas não foi detalhada por nenhum dos autores.

Assim, do estado atual das discussões sobre contrapartidas na política industrial, conclui-se que tal debate tem de avançar no sentido de, além das contrapartidas tradicionais, propor medidas que sinalizem um efetivo comprometimento das empresas apoiadas com a política governamental vigente. Ou seja, deve ficar claro que as agências governamentais responsáveis por esta área têm de exigir, além das contrapartidas tradicionais, o estabelecimento de compromissos ainda mais "críveis" para justificar o dinheiro público empregado com as políticas industriais verticais.

Com este objetivo, o presente artigo propõe, para reforçar a credibilidade do comprometimento dos agentes apoiados por certa política industrial, que tais agentes sejam estimulados a comprometer ativos específicos nas atividades que exercem e que são apoiadas pelo governo.

O comprometimento de ativos específicos, dado seu caráter de irreversibilidade, reforçaria o compromisso dos agentes apoiados no sentido de alcançar as metas que são estabelecidas para justificar o gasto do dinheiro público. E que seriam acompanhadas (de forma transparente para a sociedade) ao longo do tempo pela agência governamental responsável pela implementação da política industrial. $\mathrm{Na}$ verdade, haveria uma relação de "cooperação" (formalizada em um contrato) entre tal agência e cada empresa apoiada pela política industrial.

Com isso, fica claro que, a partir do momento em que um governo decide adotar políticas industriais verticais, podem ser colocadas em prática com maior observância das normas mais elementares de transparência e eficiência na utilização dos recursos da sociedade. Para entendermos melhor esta idéia, antes é necessário apresentar a relação existente entre os ativos específicos e o estabelecimento de compromissos críveis numa relação de cooperação.

\section{COMPROMISSOS CRÍVEIS A PARTIR DA ANÁLISE DE WILLIAMSON}

$\mathrm{Na}$ teoria de contratos de Williamson, a questão dos ativos específicos é fundamental. Como se sabe, ativos específicos são "ativos especializados que não podem ser reempregados sem sacrifício do seu valor produtivo se contratos tiverem que ser interrompidos ou encerrados prematuramente" (Williamson, 1985d: 63). Sua importância reside no fato de que sua presença faz com que a identidade dos participantes da transação, assim como a continuidade dos vínculos estabelecidos 
entre eles, ganhe uma dimensão econômica fundamental - as interações entre os agentes deixam de ser impessoais e instantâneas, o que acarreta custos para gerilas e conservá-las. ${ }^{11}$

Existem pelo menos quatro tipos diferentes de ativos específicos (ver Williamson, 1985; e Pondé, 1993: 40): ${ }^{12}$

- Especificidade locacional: refere-se à exigência de proximidade geográfica entre as partes que transacionam.

- Especificidade de ativos físicos: refere-se a unidades de capital fixo que são especializadas e atendem a requerimentos particulares da outra parte envolvida na relação.

- Especificidade de ativos humanos: refere-se às diferentes formas de aprendizado, que fazem com que demandantes e ofertantes de determinados produtos acabem se servindo mutuamente com maior eficiência do que poderiam fazer com novos parceiros.

- Ativos dedicados: referem-se à expansão de capacidade produtiva direcionada e dimensionada unicamente para atender à demanda de um conjunto de transações, implicando uma inevitável ociosidade no caso de interrupção da relação.

Antes de entrarmos na questão dos compromissos críveis a partir de ativos específicos, é importante ressaltar que estudos empíricos envolvendo tais tipos de ativos seriam mais produtivos se sempre se apresentassem passíveis de mensuração. Porém, infelizmente isso não é comum. Embora seja mais fácil mensurar ativos específicos como os "dedicados" e os "físicos", por outro lado ativos como os "humanos", que são intangíveis, obviamente não apresentam esta facilidade. Assim, aplicações empíricas interessantes sobre o tema, como a feita por Dyer (1997), não podem ser mais desenvolvidas por causa das medidas ainda precárias de ativos específicos (e também de custos de transação) utilizadas. Sem contar que tais ativos, dadas suas características de especificidade, apresentam dificuldades de realização em mercado (pela conseqüente falta de mercados secundários), o que dificulta ainda mais tais tentativas de mensuração de valor.

Porém, mesmo com estas dificuldades, este artigo parte do princípio de que se podem propor contrapartidas de política industrial a partir de ativos específicos, principalmente se forem "físicos" e "dedicados". Estes ativos, inclusive pelo caráter tangível que apresentam, podem ser medidos pelo seu valor de compra. A

\footnotetext{
${ }^{11}$ Além disso, é sempre importante lembrar a característica de escassez que este ativo apresenta, dada sua natureza específica, o que o coloca como uma importante fonte potencial de criação de vantagens competitivas para as empresas.

${ }^{12}$ Além destes, em outro texto Williamson identifica mais dois tipos de ativos específicos: os ativos brand name capital e a especificidade temporal (ver Williamson, 1996a: 105-106).
} 
ausência de mercados secundários evidentemente dificulta o acompanhamento da evolução do valor ao longo do tempo, mas alternativas como a atualização de tais valores por índices de preço mostram-se interessantes, viabilizando sua utilização como contrapartida de política industrial.

Passando à questão dos ativos específicos enquanto compromissos críveis, sabe-se que uma tentativa já clássica de teorização sobre este tema é o modelo de "refém" de Williamson (1985). O modelo de refém parte do princípio de que um tipo de salvaguarda muito utilizado nas economias capitalistas é o contrato legal. Porém, quando a especificidade dos ativos cresce, os agentes tenderão a escrever contratos cada vez mais complexos, com cláusulas contingentes que permitam ajustes eqüitativos quando as condições de mercado mudarem. Dada a complexidade cada vez maior, e seu alto custo de elaboração, os agentes podem buscar meios alternativos de salvaguardar as transações. Assim, embora os contratos sejam vistos como os principais modos de salvaguardar transações nas economias capitalistas, vários meios alternativos normalmente são colocados em prática pelos agentes.

Tais meios alternativos, que Williamson reúne sob a denominação "ordenamento privado", constituem-se de vários tipos de acordos "auto-executáveis". Entre estes, um tipo de salvaguarda muito comum é o estabelecimento de compromissos críveis. Os compromissos críveis, por sua vez, podem ser de vários tipos, mas estamos aqui interessados naqueles sob a forma de "reféns", mais especificamente reféns a partir de investimentos em ativos específicos, devido à sua ampla utilização em acordos de cooperação (servindo, portanto, como um exemplo significativo de compromissos críveis).

Williamson desenvolveu, nos capítulos 7 e 8 do seu livro de 1985, um modelo simples de refém, dividido em duas partes: na primeira são tratados os investimentos em ativos específicos feitos de forma unilateral, e na segunda, o intercâmbio bilateral. Tal modelo, segundo o autor, permite que o conceito de capital específico se estenda para além de seus usos anteriores, e mostra como pode surgir a confiança em transações recorrentes (Williamson, 1985: 169).

No caso específico do intercâmbio bilateral, o problema é como o comprador e o vendedor podem tentar expandir a relação contratual para além de seus limites "naturais", criando assim uma relação de confiança mútua. Williamson ilustra esta questão com os ativos dedicados, que são o tipo de ativo específico que se põe em risco com o intercâmbio unilateral a longo prazo, mas que se vê protegido por um acordo de intercâmbio recíproco. Neste caso, o encerramento prematuro do contrato por parte do comprador deixaria o fornecedor com um grande excesso de capacidade que somente poderia ser eliminado a preços muitos baixos. Este risco se reduziria exigindo dos compradores que entreguem um refém, embora se criaria outro: o provedor poderia manobrar para expropriar o refém. Por outro lado, o intercâmbio recíproco apoiado por inversões separadas, porém concorrentes em ativos específicos, provê uma salvaguarda mútua contra esta segunda classe de riscos. 
"Os reféns assim criados têm ademais a interessante propriedade de que jamais são trocados. Pelo contrário, cada parte conserva a posse de seus ativos dedicados, para o caso de um encerramento prematuro do contrato" (Williamson, 1985: 199, grifos originais). O resultado disso tudo é que tais procedimentos acabam intensificando a dependência mútua e reforçando os laços de cooperação.

Devemos agora mostrar como o modelo de refém, a partir daqui referindo-se ao comprometimento mútuo de ativos específicos, relaciona-se com a busca de economia de custos de transação por parte dos agentes e a conseqüente geração de vantagens competitivas. A teoria dos jogos permite caminhar nesta direção, visualizando os contratos e a cooperação de forma dinâmica.

Passando à referida abordagem, os estudos de Parkhe (1993) e Dyer (1997) são interessantes por resumir as principais contribuições teóricas no que se refere à cooperação a partir da teoria dos jogos, juntamente com alguns insights da abordagem dos custos de transação. Estudando, respectivamente, redes de subcontratação e alianças estratégicas, estes autores mostram (inclusive com evidências empíricas) como podem ser teoricamente integrados os temas relativos a compromissos críveis (notadamente o "comprometimento mútuo de ativos específicos") 13 e comportamentos dos agentes (oportunista e de confiança), considerados de fundamental importância para o entendimento da busca de eficiência e de competitividade por parte de qualquer arranjo cooperativo. Considera-se que estes elementos teóricos podem conjuntamente influenciar a magnitude dos custos de transação ao longo do tempo em um relacionamento cooperativo, e, portanto, sua eficiência e as chances de criação de vantagem competitiva.

No caso da teoria dos jogos, o ponto de partida aqui é o "dilema do prisioneiro". Como é notório, a lógica implacável de tal dilema e a inerente instabilidade introduzida dentro da relação cooperativa pela incerteza de cada parceiro, avaliando o próximo movimento do outro, podem levar a estratégias deliberadas que não necessariamente aceitam as circunstâncias como dadas, mas em vez disso buscam reformatar a estrutura da aliança para criar as condições para uma cooperação robusta (ver também Axelrod, 1984).

Por meio de tais expectativas de reciprocidade - e seu corolário, os ganhos antecipados da cooperação mútua - o futuro "joga uma sombra sobre o presente", nos termos de Axelrod, afetando os padrões correntes de comportamento. Assim, longos horizontes de tempo, interações freqüentes e alta transparência comportamental encorajam o comportamento recíproco. Estes fatores alongam a sombra do futuro e promovem resultados cooperativos, sugerindo que "a performance de uma aliança estratégica será positivamente relacionada ao tamanho da 'sombra do futuro' que é jogada" (Parkhe, 1993: 801; e Dyer, 1997). Por exemplo, a evidência empírica mostra que ativos específicos alongam a sombra do futuro,

${ }^{13}$ Conforme o "modelo de refém” de Williamson. 
sinalizando intenções de boa-fé e longos horizontes de tempo (Parkhe, 1993: 800; e Dyer, 1997).

Outra contribuição importante da teoria dos jogos refere-se à possibilidade de uma análise integrada dos comportamentos que surgem no decorrer de um relacionamento cooperativo, basicamente os de confiança e oportunista.

Em um ambiente de reputação questionável, ou ausência de qualquer reputação, o desenho de estruturas de governance apropriadas deve ser pelo menos parcialmente uma função da probabilidade percebida de oportunismo. Sabe-se que percepções de alto oportunismo podem levar a níveis de performance menores (devido aos maiores custos de transação), sugerindo que a performance de uma aliança estratégica será negativamente relacionada à extensão em que cada parte percebe a outra como se comportando oportunisticamente (Parkhe, 1993: 802-803).

A percepção de comportamento oportunista, porém, não é constante dentro de uma dada relação. Muitas perspectivas teóricas que buscam explicar sua progressiva diminuição com uma crescente história cooperativa centram a análise sobre seu "contrário psicológico", a confiança. Com isso, conclui-se, dadas as evidências empíricas, que o nível de percepção do comportamento oportunista será negativamente relacionado à história da cooperação entre os parceiros em uma aliança estratégica (Parkhe, 1993: 803).

A confiança e a história da cooperação aumentam ainda mais sua importância se levarmos em conta que os compromissos críveis não são necessariamente compromissos invioláveis. Embora sugerindo uma estratégia de cooperação, eles não oferecem garantias de cláusulas rígidas de não-defecção perante circunstâncias mutáveis, tais como os ganhos de trapacear quando estes acabam excedendo a perda de investimentos não recuperáveis. ${ }^{14}$

Daí a importância de desenvolver relações de confiança e da história de cooperação entre os parceiros como meios de reduzir o risco de surgimento de comportamento oportunista, aumentando com isso as chances de melhor performance do arranjo cooperativo em questão.

Portanto, desta breve exposição sobre as aplicações do modelo de "refém" e da teoria dos jogos às relações contratuais da cooperação, conclui-se que as questões do comprometimento de ativos específicos e dos comportamentos que surgem

\footnotetext{
${ }^{14}$ Dyer (1997: 537) nota que investimentos assimétricos em ativos específicos não reduzem a probabilidade de oportunismo; pelo contrário, até aumentam o potencial para o comportamento oportunista. Segundo ele, somente investimentos simétricos em ativos especializados reduzirão a probabilidade de oportunismo. Mas esta afirmação do autor tem de ser vista com cuidado, principalmente em casos em que os tamanhos das empresas são muito diferentes. Nestas situações, poder-se-ia pensar em um comprometimento de ativos proporcional ao tamanho das empresas, cuja comparação seria feita medindo-se para as integrantes do arranjo a proporção entre o tamanho (valor) dos seus ativos específicos comprometidos naquela relação e o tamanho da empresa (medido pela magnitude do capital ou das vendas). Porém, mesmo com medidas como esta, a incerteza quanto ao comportamento do parceiro continuaria grande.
} 
durante uma relação de cooperação podem ser mais bem explicadas, inclusive em termos da sua influência sobre o desempenho de um acordo de cooperação, com a utilização destes instrumentais teóricos.

Tais conclusões - e outros pontos importantes — podem ser ilustrados empiricamente com o estudo feito por Dyer (1997) a respeito das relações entre montadoras automobilísticas e seus fornecedores nos EUA e no Japão, que oferece dados que indicam que os custos de transação não necessariamente aumentam com um incremento nos investimentos específicos à relação. Este estudo procurou examinar as condições sob as quais os agentes podem simultaneamente atingir os "benefícios gêmeos" da alta especificidade de ativos e baixos custos de transação. Isso é possível porque diferentes salvaguardas que podem ser empregadas para controlar o oportunismo têm diferentes custos de montagem e resultam em diferentes custos de transação com diferentes horizontes de tempo.

Assim, o fato de as firmas poderem simultaneamente atingir os "benefícios gêmeos" da alta especificidade dos ativos e baixos custos de transação, uma condição que se revela importante fonte de vantagem competitiva, pode levar ao surgimento de importantes insights para o estudo da colaboração interfirmas (Dyer, 1997: 536). ${ }^{15}$ Estes achados parecem a princípio inconsistentes com a teoria dos custos de transação, que propõe que os custos de transação crescem com um incremento em investimentos específicos. Mas isso seria uma interpretação apressada das idéias de Williamson, deixando de lado por exemplo o seu modelo de refém.

Resumindo o estudo de Dyer, este autor propõe um modelo de colaboração interfirmas que maximiza o valor das transações da seguinte forma: um incremento na confiabilidade dentro da relação de troca reduz os custos de transação e aumenta a possibilidade de os agentes investirem em ativos específicos à relação. Além disso, maiores investimentos em ativos especializados servem para reforçar a promessa de credibilidade dos agentes, incrementando o custo de defecção unilateral e aumentando a "sombra do futuro". Finalmente, custos de transação mais baixos e maiores investimentos em ativos especializados maximizam o valor da transação e o desempenho conjunto dos agentes (Dyer, 1997: 550-551).

Juntando estas contribuições de Dyer com as anteriormente apresentadas a partir do trabalho de Parkhe, as principais conclusões dos trabalhos dos dois autores podem ser resumidas da seguinte forma: ${ }^{16}$ um nível de confiança maior (ou menor risco de oportunismo) está correlacionado a um maior comprometimento de ativos específicos, e ambos (juntos) constituem-se em causa de menores custos de transação, e portanto de maiores chances de criação de vantagem competitiva

\footnotetext{
${ }^{15}$ Dyer inclusive propõe medidas para os custos de transação e a especificidade dos ativos, aplicadas à indústria automobilística (Dyer, 1997: 540).

${ }^{16}$ Maiores detalhes podem ser encontrados nos próprios textos dos autores, ou em Grassi (2004).
} 
(e/ou de ampliação das já existentes). Obviamente, a relação entre ativos específicos e vantagem competitiva também pode ser direta, dadas as características deste tipo de ativo (neste caso, sua relativa escassez). O Quadro 1, a seguir, ilustra estas observações:

Quadro 1: compromissos críveis, comportamentos e custos de transação

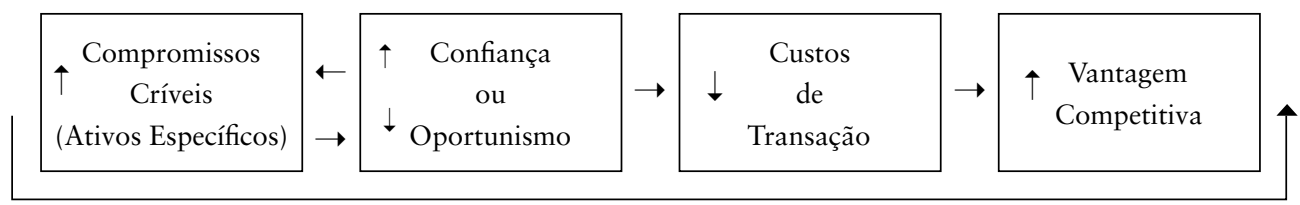

Com isso, podemos concluir que, a partir das contribuições de autores como Williamson, Parkhe e Dyer, surge um esquema teórico interessante para entender melhor os diversos tipos de cooperação entre empresas, e como elas evoluem no tempo, inclusive com seus efeitos em termos de criação de vantagens competitivas por parte dos agentes que cooperam.

O desafio agora é adaptar estas idéias para entender a "cooperação" que existe entre uma empresa e uma agência governamental que coloca em prática a política industrial de um país ou região.

\section{POLÍTICA INDUSTRIAL E COMPROMISSOS CRÍVEIS: UMA PROPOSTA DE ANÁLISE E DE AÇÃO GOVERNAMENTAL}

\section{Apresentação dos atores}

Podemos passar agora à análise de como os elementos teóricos vistos na seção anterior, e voltados para o entendimento de como se gera confiança ao longo do tempo em relações empresariais de cooperação, podem ser usados para entender uma relação particular de "cooperação" entre cada empresa apoiada pela política industrial (vertical) vigente e a agência pública encarregada de colocá-la em prática.

Cada parte neste "jogo" teria seu objetivo a ser alcançado: a empresa buscando a criação de vantagens competitivas (ou a ampliação das que já possui) e com isso maiores níveis de lucratividade; e a agência pública buscando a maximização do benefício para a sociedade decorrente do dinheiro público aplicado com a política industrial (este resultado seria sua "vantagem competitiva", inclusive em termos de sucesso na carreira ou dividendos eleitorais para o gestor público que a administra).

Obviamente, como em qualquer relação de cooperação, a confiança gerada ao longo do tempo é fundamental para o sucesso do acordo entre as partes. E, como visto no caso da cooperação entre empresas, altos níveis de confiança também 
estariam relacionados com a colocação de "reféns" na relação. O governo colocaria como "refém" o dinheiro público, que, se não for empregado adequadamente, significará prejuízo para a sociedade (podendo também significar punições para o administrador público, se neste caso ficar demonstrada má-fé) ${ }^{17} \mathrm{~A}$ empresa apoiada, por sua vez, comprometeria ativos específicos naquela atividade econômica incentivada pela política industrial vigente, sinalizando de forma confiável que pretende investir nela de forma constante nos próximos anos, reforçando as contrapartidas mais tradicionais com as quais teria antes de se comprometer.

Nesta situação, os dois agentes não poderiam mais facilmente ser oportunistas, pois sairiam perdendo com este tipo de comportamento. Vale ressaltar, embora a relação acima não se aproxime do caso ideal de reféns "não trocados", pois os recursos da política governamental estariam de posse da empresa em questão, fica claro que nos casos dos dois “jogadores” o rompimento da cooperação significaria perdas. Para o governo, haveria perda dos recursos; e para a empresa, a perda estaria concretizada no fato dela passar a possuir um ativo que, por sua característica de especificidade, não seria mais facilmente revendido no mercado.

\section{A nova dinâmica da política industrial}

Passando à dinâmica da política industrial a partir da descrição dos dois atores acima, ela ocorreria da seguinte forma: dados os objetivos da política industrial vigente, seriam escolhidos os setores a ser apoiados pela política, e especificadas as contrapartidas tradicionais. A partir daí, empresas que desejassem um apoio maior, além de cumprir as contrapartidas tradicionais, passariam a se comprometer a investir com recursos próprios em ativos específicos voltados para aquela atividade.

Tal comprometimento seria acompanhado (de forma transparente para a sociedade) ao longo do tempo pela agência governamental responsável pela implementação da política industrial, revelando uma relação de "cooperação" (formalizada em um contrato que especifique todas as contrapartidas utilizadas) entre tal agência e cada empresa apoiada pela política industrial.

Algumas observações podem ajudar a detalhar melhor a idéia acima exposta:

1) Como é notório, compromissos críveis não são invioláveis. Eles são importantes no esforço de evitar a adoção de comportamentos oportunistas por parte de agentes numa relação de cooperação, mas não conseguem eliminar totalmente tal risco. Por isso, os ativos específicos não podem ser o único tipo de contrapartida exigido pelas autoridades governamentais. Assim, o que se está propondo neste texto não é a substituição das contrapartidas mais tradicionais pela aqui proposta, mas a atuação de todas em conjunto.

\footnotetext{
${ }^{17}$ Estes seriam os casos, por exemplo, de empréstimos com condições facilitadas sem as devidas garantias bancárias, e de renúncia fiscal que não acompanhe as normas legais mínimas.
} 
2) Além disso, a colocação em prática deste novo tipo de contrapartida não altera em nada o cumprimento das metas quanto a resultados que cada vez mais as políticas industriais devem exigir dos setores e empresas apoiados. Os resultados continuariam a ser exigidos a partir de contrapartidas tradicionais como metas de exportações e de custos, que as empresas seriam obrigadas a cumprir. O que muda é que, com a nova contrapartida (à qual as empresas teriam a opção de aderir ou não), elas se sentiriam ainda mais estimuladas para cumprir as metas acordadas em busca de criação e/ou ampliação de vantagens competitivas (já que ao mesmo tempo estariam investindo parcela maior de recursos próprios na atividade econômica em questão, e com isso obtendo mais recursos do governo).

3) Em nenhum momento a proposta acima exposta significa maior utilização de recursos com a política industrial por parte das autoridades governamentais. Ela apenas propõe melhor utilização do montante inicial, a partir da colocação em prática de mais um tipo de contrapartida, juntamente com as contrapartidas tradicionais. O objetivo passa a ser a manutenção das contrapartidas mais tradicionais e a utilização crescente de ativos específicos como uma nova contrapartida que se soma às anteriores (começando com um pequeno percentual dos recursos disponíveis para a política industrial vertical, que pode ser ampliado ao longo do tempo). Nesta nova dinâmica, empresas que comprometerem mais ativos específicos evidentemente terão mais recursos disponíveis (em detrimento das que não o fizerem). Isto revela mais uma vez o forte caráter de incentivo à adequação das empresas aos objetivos da política industrial vigente que esta nova contrapartida apresenta. ${ }^{18}$

4) A proposta acima somente pode funcionar a contento se a agência governamental responsável pela colocação em prática da política industrial tiver meios de averiguar se o comprometimento da empresa apoiada se dá a partir de ativos específicos adquiridos com recursos próprios da empresa. O que não pode acontecer em nenhuma hipótese, pois anularia os possíveis efeitos benéficos em termos de incentivos à eficiência da empresa apoiada, é ela receber algum tipo de auxílio da política industrial vigente e adquirir os ativos específicos a partir destes recursos.

5) Evidentemente, o mecanismo de política acima proposto somente pode funcionar a contento se adotado com a maior transparência possível, a partir de uma agência governamental de sólida reputação no país ou região em questão, reputação esta refletida em regras claras quanto à duração e tamanho dos benefícios recebidos, contrapartidas exigidas e punições efetivas para agentes beneficiados e gestores públicos que atuarem fora das condições legais. Em muitos países, sabe-se

\footnotetext{
${ }^{18}$ E neste contexto caberia à agência governamental encarregada da política industrial determinar qual a proporção ideal entre os recursos públicos liberados para cada empresa e o valor dos ativos específicos por ela comprometidos. Supondo que se comece com uma proporção de uma unidade monetária pública para cada unidade monetária privada, com o tempo e o sucesso da política (no sentido de muitas empresas se interessarem pelo novo incentivo), a proporção poderia passar a ser de uma unidade monetária pública para um valor privado mais elevado.
} 
que a política industrial é mais uma fonte de má utilização dos recursos públicos (principalmente em seus componentes verticais), e um mecanismo de política como o aqui proposto, que tem como um dos principais objetivos coibir este tipo de prática, não pode se tornar mais uma fonte deste tipo de desperdício. Para usar um termo muito comum na área de regulação de monopólios naturais (e neste caso a presente proposta se beneficiaria muito aprendendo sobre a experiência prática da referida área), a agência não pode ser "capturada" pelas empresas por ela apoiadas.

6) A política industrial deve também levar em conta que certos setores são mais intensivos em ativos específicos que outros. ${ }^{19}$ Por exemplo, quanto maior o conteúdo tecnológico dos processos e produtos de um setor, provavelmente mais ativos específicos (como os "humanos") serão comprometidos pelas empresas da sua cadeia produtiva. Uma comparação entre um setor mais tradicional como o de confecções, de um lado, e o de biotecnologia, de outro, mostra claramente que neste último o grau de utilização de ativos específicos humanos tende a ser maior. ${ }^{20}$ Por isso, a política industrial tem de estar preparada para lidar com as demandas dos mais diferentes setores, separando-os por grau de utilização de ativos específicos. Caso contrário, setores intensivos em ativos específicos poderão ser beneficiados em detrimento dos pouco intensivos.

\section{Ativos específicos e política industrial e tecnológica}

A presente proposta tem de se posicionar também quanto ao fato de que cada vez mais a política industrial nos diversos países que a adotam é "política industrial e tecnológica". Ou seja, é muito comum atualmente as políticas industriais horizontais apresentarem fortes incentivos à inovação, e as verticais elegerem estrategicamente como prioridade a adoção de incentivos para setores de elevado conteúdo tecnológico ou que podem "espalhar" tal desenvolvimento tecnológico para outros setores da economia. Nestes casos também a presente proposta é importante, pois o estímulo ao comprometimento de ativos específicos por parte do meio empresarial, dada a característica peculiar de tal ativo de escassez, revelando potencial inovativo (inclusive no caso dos ativos específicos que não são diretamente relacionados ao aprendizado, como é o caso dos ativos "físicos" e "dedicados”), pode ser importante para ampliar tal potencial inovativo em uma região ou país. Além disso, uma empresa que tem planos de inovar terá de ter recursos para tal, e a política aqui proposta é uma forma de obter tais recursos, conforme visto anteriormente.

\footnotetext{
${ }^{19}$ Agradeço a sugestão deste item a um parecerista anônimo.

${ }^{20}$ Pisano (1990), utilizando dados sobre projetos de P\&D em biotecnologia que grandes companhias farmacêuticas têm realizado, mostra inclusive que problemas de custos de transação motivam as firmas a internalizar o P\&D.
} 
Mas não é só isso. Quando medidas de política industrial se referem a atividades inovativas (como as voltadas para P\&D, por exemplo), evidentemente os resultados futuros são altamente incertos, pois nem a própria empresa tem garantia de que uma inovação colocada em prática será bem-sucedida. Sabe-se inclusive que nestes casos, como medidas de estímulo, é recomendável ao setor público ao mesmo tempo tentar mitigar os riscos a eles inerentes ${ }^{21}$ e arcar com uma parte destes custos, e para isso pode ser importante também uma cobrança mais "branda" (para compensar tal risco) no que se refere às contrapartidas tradicionais normalmente exigidas. ${ }^{22}$

Porém, para a política aqui proposta, haveria a mesma exigência de comprometimento de ativos específicos (para obter maiores estímulos governamentais), e devendo-se atentar que neste caso, na maior parte das vezes, os ativos comprometidos poderiam ser os "humanos" (que são intangíveis), como forma de a empresa sinalizar compromisso com a política industrial vigente. ${ }^{23}$ É importante ressaltar, que com esta proposta não ficaria caracterizada a obrigação de a empresa apresentar algum resultado inovativo ao ter de comprometer ativos específicos (o que poderia desestimulá-la de exercer atividades inovativas), embora tal resultado seja uma possível conseqüência desse comprometimento, que, este sim, seria obrigatório caso quisesse ter mais recursos do governo. ${ }^{24} \mathrm{E}$ mais uma vez ressaltando que o pleno funcionamento deste mecanismo de política depende da colocação em prática de uma efetiva atividade fiscalizadora sobre os recursos governamentais utilizados pelas empresas.

Com tudo isso, conclui-se que a proposta de contrapartida a partir de ativos específicos elaborada neste artigo divide-se em duas situações básicas:

- Uma situação como a descrita na subseção anterior, mais voltada para atividades pouco inovativas e/ou que exigem forte presença de capital fixo (como

\footnotetext{
${ }^{21}$ Considerando-se que incentivar inovações é fundamental para se buscar a competitividade no mundo econômico atual, e dado seu caráter altamente incerto, é interessante a criação por parte dos governos (e mesmo por parte de agentes privados) de mecanismos específicos para lidar com tal incerteza. Sicsú e Albuquerque (2002), por exemplo, propõem a criação de uma agência pública voltada para o financiamento da inovação, a Agência Especial de Seguros (AES).

${ }^{22}$ Embora neste caso mecanismos fiscalizadores do dinheiro público utilizado sejam ainda mais necessários do que em outros casos, para evitar que o dinheiro destinado para a inovação das empresas tenha outros fins.

${ }^{23}$ Um exemplo interessante aqui se refere aos gastos com capacitação, como no caso da contratação de mestres e doutores por parte das empresas. Este caso é interessante inclusive porque está sendo proposto na recente "Lei do Bem" brasileira (Lei n 11.196, de 21/11/05, cap. III, regulamentada pelo Decreto $\mathrm{n}^{\circ} 5.798$, de 07/06/06). E mostra que ativos intangíveis podem de alguma forma ser mensurados, pois neste caso teríamos como base para tal mensuração o pagamento dos salários destes profissionais.

${ }^{24}$ É o que parece sugerir a "Lei do Bem”, ao estabelecer que o governo pagará certa porcentagem dos salários destes profissionais. Assim, fica claro que quem contratar mais mestres e doutores obterá mais subsídios governamentais.
} 
nos casos de ativos "dedicados" e "físicos"), nas quais tanto as contrapartidas tradicionais como a aqui proposta (a partir de ativos específicos) seriam exigidas;

- Uma situação como a descrita nesta subseção, voltada para atividades essencialmente inovativas (baseadas em ativos "humanos", por exemplo), nas quais as contrapartidas tradicionais seriam abrandadas (e ao mesmo tempo acompanhadas de forte fiscalização), mas com a exigência de contrapartidas a partir de ativos específicos para a obtenção de maior volume de recursos, da mesma forma que no caso anterior.

\section{CONCLUSÃO}

Este artigo procurou mostrar que políticas industriais podem aumentar seu nível de eficiência no sentido de alcançar melhores resultados para a sociedade a partir da sua adoção. Evitou-se entrar no mérito sobre se é necessário ou não um país ou região ter políticas industriais, principalmente as verticais. Apenas partimos do ponto de vista de que elas existem em boa parte dos países, e que por isso podem (e devem) ser aperfeiçoadas no seu calcanhar-de-aquiles, que se refere à possibilidade de uso indevido dos recursos da sociedade.

A proposta acima procurou adaptar uma idéia que vem mostrando ser efetiva em termos de resultados alcançados na cooperação interfirmas privada, para a questão da cooperação firma-agência pública (encarregada da política industrial). Mostrou-se que o governo pode - sem a utilização de mais recursos públicos do que os iniciais - ampliar e sofisticar as contrapartidas que os agentes assumem quando são apoiados por medidas de política industrial, criando-se uma nova contrapartida a partir de ativos específicos, que tem forte caráter de incentivo no sentido de as empresas apoiadas cumprirem melhor as contrapartidas tradicionais por elas assumidas.

Embora não se deva esquecer que compromissos críveis não são invioláveis, e que compromissos críveis a partir de ativos específicos apresentam certa dificuldade de mensuração, acreditamos que a proposta acima, dada a força da idéia que a sustenta (como comprovado em estudos empíricos sobre cooperação entre empresas), pode sem dúvida ampliar o debate atual sobre contrapartidas na execução de políticas industriais, e até mesmo aperfeiçoar sua aplicação prática (reforçando seus mecanismos de incentivo), no sentido de serem utilizadas com maior transparência e eficiência.

E isto num momento oportuno, em que o Brasil vem novamente discutindo nos últimos anos, depois de certo lapso de tempo, a utilização pelo governo de políticas industriais (tanto seus componentes verticais como os horizontais). E devendo-se ressaltar que a nova Política Industrial, Tecnológica e de Comércio Exterior (PITCE), colocada em prática a partir de 2003, apresenta um desenho institucional bastante interessante, com a colocação em funcionamento de uma 
agência governamental direcionada para tal fim, a Agência Brasileira de Desenvolvimento Industrial (ABDI).

Porém, ao acompanhar o debate recente sobre tal política (cujo componente vertical se efetiva ao selecionar inicialmente como estratégicos os setores de fármacos e medicamentos, software, semicondutores e bens de capital, além dos "portadores de futuro", como biotecnologia e nanotecnologia), nota-se uma análise no mínimo superficial da questão das contrapartidas, tanto no que se refere aos objetivos da referida política, como também a alguns de seus primeiros resultados práticos (ver Governo Federal, 2003; Carvalho, 2005; e MDIC, 2006).

Por outro lado, dois mecanismos (de caráter horizontal) relacionados à nova PITCE mais recentemente colocados em funcionamento (a "Lei de Inovação" e a "Lei do Bem", esta última no seu capítulo III $)^{25}$ já apresentam de forma mais clara a exigência de contrapartidas e até mesmo punição por uso indevido dos incentivos (ver as referidas leis e também Salerno e Daher, 2006), e chegando inclusive à exigência de compromissos como proposto neste artigo (no caso específico do incentivo para a contratação de mestres e doutores para exercerem atividades inovativas nas empresas).

Porém, apesar dos objetivos ambiciosos em termos de impulso à inovação contidos nestes novos mecanismos, tem de ser ressaltado que o bom uso do dinheiro público neles depende em grande parte da fiscalização dos órgãos públicos competentes, conforme visto anteriormente, e conforme fica explicitado nas duas leis. Por isso, uma análise de custo-benefício será necessária, num futuro próximo, para avaliar a efetividade das medidas recentes de política industrial no sentido de tornar a indústria brasileira mais inovativa. Neste caso, também é importante que estas medidas que estão começando a ser colocadas em prática tenham um mínimo de continuidade (ao contrário de medidas anteriores de política industrial), para que os resultados possam ser avaliados.

Com tudo isso, a colocação em prática da nova política pode ser importante para se aprofundar a discussão sobre contrapartidas na política industrial. $\mathrm{Ou}$ seja, é importante ressaltar que, embora este artigo considere importante a discussão sobre o mecanismo de contrapartida na política industrial a partir do comprometimento de ativos específicos (que é complementar às contrapartidas mais tradicionais), no caso específico do Brasil verifica-se que mesmo a discussão das contrapartidas tradicionais ainda tem de avançar consideravelmente. Sem dúvida, a ampla discussão sobre os mais variados tipos de contrapartida (tradicionais e a aqui proposta) pode ter papel importante para a recém-criada ABDI, e a colo-

\footnotetext{
${ }^{25}$ A "Lei de Inovação" foi estabelecida pela Lei n 10.973 (de 02/12/04) e regulamentada pelo Decreto $\mathrm{n}^{\circ} 5.563$ (de 11/10/05); e a "Lei do Bem" foi estabelecida pela Lei n 11.196 (de 21/11/05) e regulamentada pelo Decreto $\mathrm{n}^{\circ} 5.798$ (de 07/06/06). Estas leis subvencionam de várias formas a inovação nas empresas. Além delas, a nova PITCE conta também com mecanismos com esta finalidade via BNDES e FINEP, entre outros (ver Salerno e Daher, 2006).
} 
cação em prática de mecanismos como os acima mencionados (Leis do Bem e da Inovação) são uma oportunidade neste sentido.

Assim, a idéia acima proposta neste artigo contribui no sentido de que, se é para haver novamente políticas industriais ativas, principalmente as de corte vertical, que elas mesmas não repitam os erros de um passado não muito remoto, no qual os diversos tipos de política industrial colocados em prática não exigiram contrapartidas sólidas das empresas apoiadas (ao contrário de alguns países asiáticos), nem foram executados com transparência, revelando-se no final em muitos casos apenas mero instrumento de apropriação privada de consideráveis recursos da sociedade brasileira.

\section{REFERÊNCIAS BIBLIOGRÁFICAS}

AXELROD, R. (1984) The Evolution of Cooperation, New York, Basic Books.

CARVALHO JR., A. M. (2005) “A Política Industrial e o BNDES”, Revista do BNDES, vol. 12, nº 23, jun., Rio de Janeiro.

CASSIOLATO, J. E. (2003) "Políticas de Desenvolvimento Industrial para o Brasil: Lições da Experiência Internacional”, Econômica, vol. 5, n 2, dezembro.

DYER, J. (1997) "Effective Interfirm Collaboration: How Firms Minimize Transaction Costs and Maximize Transaction Value", Strategic Management Journal, vol. 18:7.

ECONÔMICA (2003) "Dossiê - Política Industrial”, vol. 5, n² 2, dezembro.

FERRAZ, J. C., de PAULA, G. M. e KUPFER, D. (2002) "Política Industrial”, in KUPFER, D. e HASENCLEVER, L. (orgs.) Economia Industrial: fundamentos teóricos e práticas no Brasil. $2^{\mathrm{a}}$ edição, Rio de Janeiro, Editora Campus.

FERREIRA, P. C. e HAMDAN, G. (2003) "Política Industrial no Brasil: Ineficaz e Regressiva”, Econômica, vol. $5, \mathrm{n}^{\circ} 2$, dezembro.

GOVERNO FEDERAL (2003) Diretrizes de Política Industrial, Tecnológica e de Comércio Exterior. Disponível em www.desenvolvimento.gov.br/arquivo/ascom/apresentacoes/Diretrizes.pdf . Acesso em 07/03/2007.

GRASSI, R. A. (1998) A Indústria Naval Brasileira no Período 1958-94: Análise Histórica de Sua Crise Atual e das Perspectivas de Mudança a Partir do Conceito Estrutural de Competitividade, Série Estudos Econômicos, Tribunal de Contas do Estado do Rio de Janeiro.

GRASSI, R. A. (2004) “Cooperação Inter-Firmas, 'Reféns' e 'Sombra do Futuro': Em Busca de uma Integração Teórica a partir de Williamson”, Economia Aplicada, vol. 8, n 1 .

MINISTÉRIO DO DESENVOLVIMENTO, INDÚSTRIA E COMÉRCIO EXTERIOR (MDIC) (2006) Balanço PITCE - 2005. Disponível em www.desenvolvimento.gov.br/arquivo/ascom/ imprensa/20060404balancoPITCE.pdf . Acesso em 07/03/2007.

NASSIF, A. (2003) “Uma Contribuição ao Debate sobre a Nova Política Industrial Brasileira”, Textos para Discussão, nº 101, Rio de Janeiro, BNDES.

NASSIF, A. (2005) "Estratégias de Desenvolvimento em Países de Industrialização Retardatária: Modelos Teóricos, a Experiência do Leste Asiático e Lições para o Brasil”, Revista do BNDES, vol. $12, \mathrm{n}^{\circ} 23$, jun., Rio de Janeiro.

PARKHE, A. (1993) "Strategic Alliance Structuring: A Game Theoretic and Transaction Cost Examination of Interfirm Cooperation", Academy of Management Journal, vol. 36, $\mathrm{n}^{\circ} 4$.

PISANO, G. (1990) "The R\&D Boundaries of the Firm: An Empirical Analysis", Administrative Science Quarterly, 35, p. 153-176.

PONDÉ, J. L. (1993) Coordenação e Aprendizado: Elementos para uma Teoria das Inovações Institucionais nas Firmas e nos Mercados, Dissertação de Mestrado, Unicamp, mimeo. 
SALERNO, M. e DAHER, T. (2006) Política Industrial, Tecnológica e de Comércio Exterior do Governo Federal (PITCE): Balanço e Perspectivas. Disponível em www.abdi.com.br/abdi_redesign/ publicacao/download.wsp?tmp.arquivo=362. Acesso em 17/03/2007.

SICSÚ, J. e ALBUQUERQUE, E. M. (2002) "O Papel de Uma Agência Especial de Seguros de Empréstimos no Brasil”, Revista de Economia Política, vol. 22, n² 2(86).

WILliAMSON, O. E. (1985) Las Instituciones Económicas del Capitalismo, México, Fondo de Cultura Económica, 1989.

WILliAMSON, O. E. (1996a) "Comparative Economic Organization: The Analysis of Discrete Structural Alternatives", in Mechanisms of Governance, Oxford University Press.

WILLIAMSON, O. E. (1996b) "Calculativeness, Trust and Economic Organization”, in Mechanisms of Governance, Oxford University Press. 